\title{
Jurnal

\section{PENGARUH PENYULUHAN KESEHATAN TERHADAP SIKAP SISWA DALAM PERAWATAN GIGI DI SDN 601 MENANGGAL SURABAYA}

\author{
The Effect of Health Promotion on Attitude of Students in Dental Care in Public Elementary \\ School 601 Menanggal Surabaya
}

\section{Etta Suryaningsih, Marcellina Rasemi Widayanti*, Ni Nyoman Wahyu Lestarina}

\author{
STIKES Katolik St. Vincentius a Paulo
}

\section{Riwayat artikel}

Diajukan: 8 Juli 2019

Diterima: 28 Maret 2020

\section{Penulis Korespondensi:}

- Marcellina Rasemi Widayanti

- STIKES Katolik St. Vincentius a Paulo

- marcellina_raswi@yaho $\underline{\text { o.co.id }}$

\section{Kata Kunci:}

Sikap Siswa, Penyuluhan Kesehatan, Perawatan Gigi

\section{Abstrak}

Pendahuluan: Pengetahuan tentang perawatan gigi pada anak SD menentukan kesehatan gigi pada usia selanjutnya. Pengetahuan baik maka diikuti sikap positif, sikap positif mempengaruhi niat. Fenomena di SDN 601 Mananggal Surabaya, siswa mengatakan tahu perawatan gigi tetapi masih menyukai makanan manis setelahnya lupa menggosok gigi atau berkumur, dan ada yang mengalami gigi karies. Hal ini dikarenakan penyuluhan kesehatan belum pernah dilakukan. Tujuan: Tujuan penelitian untuk mengetahui bagaimana penyuluhan kesehatan dapat berpengaruh terhadap sikap siswa dalam perawatan gigi. Metode: Desain penelitian Pra Eksperimental dengan rancangan One Group Pre-Post Test Design. Variabel independen penyuluhan kesehatan dan variabel dependen sikap siswa. Populasi siswa SDN 601 Menanggal Surabaya yang memenuhi kriteria inklusi. Sampel penelitian sebanyak 33 responden dengan teknik acak. Instrumen penelitian menggunakan kuesioner. Hasil: Sebelum dilakukan tindakan penyuluhan kesehatan 73\% siswa bersikap negatif, sesudah diberikan penyuluhan kesehatan $64 \%$ siswa memiliki sikap positif. Hasil uji Wilcoxon Sign Rank Test menunjukkan nilai $\mathrm{P}(0,001)<\alpha(0,05)$. Kesimpulan: $\mathrm{H} 0$ ditolak berarti ada pengaruh penyuluhan kesehatan tentang perawatan gigi terhadap sikap siswa dalam perawatan gigi sebelum dan sesudah dilakukan penyuluhan kesehatan. Diharapkan sekolah memberikan program secara berkelanjutan tentang pemberian pendidikan kesehatan.

\section{Abstract}

Background: Knowledge of dental care in elementary school children determines dental health at the next age. Good knowledge is followed by a positive attitude, a positive attitude influences intention. The phenomenon in SDN 601 Menanggal Surabaya, students knew dental care but still liked sweet foods after forgetting to brush their teeth and there were those who had carious teeth because health education has never been done. Objective: The purpose was to identify the effect of health promotion education on student attitudes in dental care. Method: Pre-experimental research design with the design of the One Group Pre-Post Test Design. Independent variables are health education and dependent variable attitudes of students. The population is students at SDN 601 Surabaya who met the inclusion criteria. The research sample was 33 respondents with Random technique. The research instrument used a questionnaire. Results: Data were analyzed using descriptive statistics proportion of percentage, results before being given health education $73 \%$ of students had a negative attitude, after being given health education 64\% of students had a positive attitude. The results of the Wilcoxon Sign Rank Test showed that the value of $P(0.001)<\alpha(0.05)$. Conclusion: HO was rejected means that there is an influence of health education on student attitudes in dental care before and after health education, health education is effective in increasing attitudes to be positive. It is hoped that the school will cooperate with the puskesmas in the making of health education programs and routine dental examinations in schools to improve health and reduce dental health problems. 


\section{PENDAHULUAN}

Perawatan gigi pada anak merupakan suatu upaya yang dilakukan agar kesehatan gigi pada anak tetap terjaga dan dapat menjalankan fungsinya (Priyoto, 2015). Pengetahuan tentang perawatan gigi pada anak Sekolah Dasar sangat penting pada usia sekolah dasar untuk selanjutnya mereka dapat melakukan perawatan gigi, perawatan gigi yang dilakukan seperti menghindari makan makanan yang manis, berkumur setelah makan, menyikat gigi teratur dan tepat waktu, dan memeriksakan gigi secara rutin ke dokter. Saat ini kesadaran anak akan pentingnya perawatan kesehatan gigi masih kurang (Ghofur, 2012).

Kurangnya perawatan kesehatan gigi pada anak tersebut dipengaruhi banyak faktor. Menurut Green yang dikutip dalam (Priyoto, 2015) mengungkapkan bahwa faktor predisposisi seperti tingkat pengetahuan dan sikap. Pengetahuan yang baik maka diikuti sikap positif, sikap positif dari seseorang akan mempengaruhi niat. Fenomena yang ditemukan di SDN 601 Mananggal Surabaya ditemukan beberapa siswa menyatakan sudah mengetahui tentang perawatan gigi akan tetapi tidak ada niat untuk melakukan perawataan gigi, mereka mengatakan bahwa mereka akan menggosok gigi pada malam hari jika mereka ingat, beberapa dari mereka juga menyatakan bahwa menyikat gigi hanya pada saat ingin berangkat sekolah dan mandi sore, beberapa dari mereka ada yang mengalami gigi karies, mereka juga suka makanan mengandung gula seperti permen, coklat dan ice cream.

Berdasarkan data dari Badan Penelitian dan Pengembangan Kesehatan Kementerian RI (Riskesdas, 2018) penduduk Indonesia yang mempunyai masalah pada gigi sebesar $57,6 \%$, untuk wilayah Jawa Timur sebesar 28,6\% yang bermasalah pada gigi. Berdasarkan data PUSDATIN Kementerian Kesehatan RI (Infodatin, 2014) proporsi masalah gigi berdasarkan kelompok usia 10-14 tahun di Indonesia sebesar $25,2 \%$. Berdasarkan penelitian Priyanti dan Septarini (2016) yang dilakukan pada anak Sekolah Dasar di Pulau Nusa Penida, Klungkung, Bali prevalensi karies gigi pada anak usia Sekolah Dasar di wilayah tersebut mencapai $53,6 \%$. Berdasarkan hasil penelitian Purwaningsih dan Sirat (2016) di SD Peguyangan, Denpasar kejadian karies paling banyak pada kelas V dan IV. Berdasarkan hasil survey pendahuluan yang dilakukan pada tanggal
1 Desember 2018 di SDN 601 Menanggal Surabaya, dari 5 orang anak terdapat 3 orang anak yang mengalami karies gigi, 5 anak mengatakan bahwa mereka akan menggosok gigi pada malam hari jika mereka ingat, 5 anak mengatakan mereka menggosok gigi 2 kali sehari saat bangun pagi serta sore waktu mandi.

Menurut Notoatmodjo yang dikutip oleh Budiman \& Agus (2014) faktor-faktor yang mempengaruhi atau merubah sikap seseorang adalah pengalaman individu, orang lain yang dianggap penting yang memberikan pengaruh, budaya, mass media, lembaga pendidikan dan lembaga agama, serta faktor psikologis/emosional. Sikap ialah kesiapan untuk bertindak, sikap dapat berupa respon secara positif atau negative terhadap suatu hal tertentu, jika anak-anak tidak mendapatkan pengalaman tentang gigi maka akan berpengaruh pada sikap anak yang tidak melakukan upaya untuk mencegah atau merawat gigi. Dampak dari sikap yang negatif dapat menimbulkan masalah kesehatan gigi seperti gigi karies, bau mulut, plak pada gigi, maupun berbagai penyimpangan yang lainnya (Priyoto, 2015).

Sesuai dengan teori Green yang dikutip oleh Notoatmodjo (2010) menyatakan bahwa perilaku individu atau sekelompok orang ditentukan salah satunya oleh sikap dari orang atau kelompok yang bersangkutan. Green mengungkapkan bahwa penyuluhan kesehatan merupakan salah satu upaya dari pendidikan atau promosi kesehatan yang berupaya ditujukan untuk menambah tingkat pengetahuan dan sikap seseorang, dimana dengan kata lain penyuluhan dapat berpengaruh positif terhadap pemeliharaan dan peningkatan kesehatan (Notoatmodjo, 2012). Adanya informasi baru tentang topik tertentu dapat memberikan landasan pengetahuan baru bagi terbentuknya sikap (Azwar, 2015), hal ini didukung oleh penelitian Sutriman (2013) yang menunjukan bahwa terdapat perbedaan yang signifikan pada sikap yang ditunjukan oleh siswa SD baik sebelum maupaun setelah dilakukan penyuluhan, dan didukung dalam penelitian Sherlyta (2017) yang mengatakan bahwa penyuluhan kesehatan gigi sangat penting diterapkan pada anak sekolah dasar umur 6-12 tahun karena pada usia tersebut adalah masa rawan terhadap pembetukan perilaku berikutnya, dengan begitu solusi yang diberikan peneliti ialah penyuluhan tentang perawatan gigi yang bertujuan untuk mengurangi atau mencegah 
terjadinya permasalahan gigi lebih lanjut. Penyuluhan ini dilakukan untuk mendukung sikap anak.

\section{METODE}

Pada penelitian ini desain yang digunakan dalam adalah pra experimental design dengan rancangan one-group pretest- postest design.

Populasi dalam penelitian ini sebesar 72 orang dan diambil sebagai responden adalah 33 siswa SDN 601 Menanggal Surabaya yang memenuhi kriteria inklusi

\section{HASIL DAN PEMBAHASAN \\ HASIL PENELITIAN}

Tabel 4.1 Karakteristik Responden Berdasarkan Data Umum Pada Siswa di SDN 601 Menanggal Surabaya.

No Variabel

$$
\begin{array}{lll}
\text { Frekuens } & (\%) & \text { Mean } \pm \\
\text { i (n) } & & \text { SD }
\end{array}
$$

Karakteristik

Responden

1. Usia

$11.15 \pm$ 0.566

$\begin{array}{ccc}10 & 3 & 9.1 \\ 11 & 21 & 63.6 \\ 12 & 9 & 27.3\end{array}$

2. Jenis

Kelamin

Laki-laki

Perempuan

57.6

3. Pernah

mendapat

informasi

tentang gigi

Ya

Tidak

21

63.6

$12 \quad 36.4$

4. Sumber

Informasi

Petugas

kesehatan

Pelayanan

kesehatan

Media

elektronik

Media cetak

8

24.2

$7 \quad 21.2$

$1 \quad 3.0$

$5 \quad 15.2$

5. Pemeriksaan

gigi secara

rutin

disekolah

$\begin{array}{lll}\text { Ya } & 10 & 30.3 \\ \text { Tidak } & 23 & 69.7\end{array}$

Sumber: Data primer (2019)

Berdasarkan hasil penelitian didapatkan data jenis kelamin sebanyak 19
(57.6\%) responden laki-laki. Bila ditinjau dari pernah mendapat informasi tentang gigi didapatkan sebanyak $21(63.6 \%)$ responden menjawab ya pernah mendapat informasi. Bila ditinjau dari sumber memperoleh informasi didapatkan hasil bahwa 8 (24.2\%) mengatakan mendapat informasi dari petugas kesehatan.

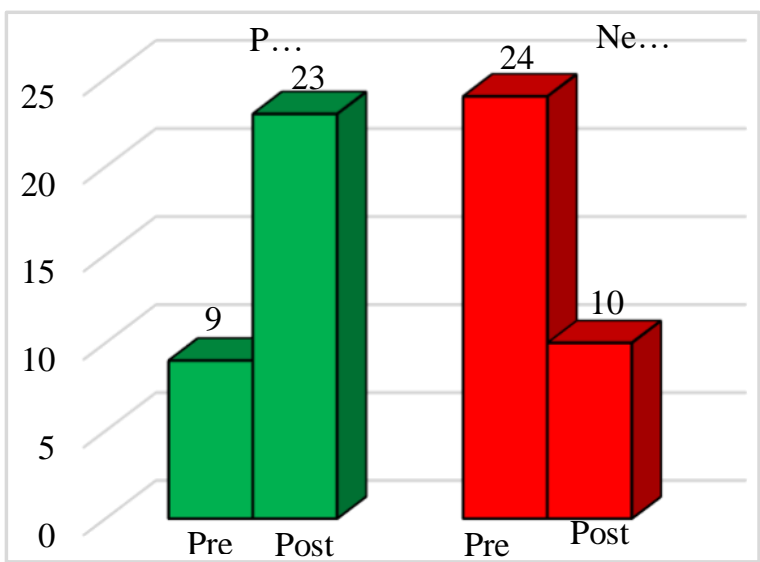

Diagram 1 Karakteristik Responden Berdasarkan Sikap Siswa Sebelum dan Sesudah Diberikan Penyuluhan Kesehatan Tentang Perawatan Gigi Pada Siswa SDN 601 Menanggal Surabaya Pada Tanggal 13 April 2019.

Berdasarkan diagram 1, sebelum dilakukan penyuluhan kesehatan didapatkan hasil sebanyak 24 responden dengan respon sikap negatif dan sebanyak 9 responden dengan respon sikap positif. Sesudah dilakukan penyuluhan kesehatan didapatkan hasil sebanyak 10 responden dengan respon sikap negatif dan sebanyak 23 responden dengan respon sikap positif. Hasil penelitian di uji dengan uji Wilcoxon menggunakan perangkat Softwere SPSS 23 for Windows, dan didapatkan hasil bahwa sikap responden terdapat perbedaan saat sebelum dan sesudah dilakukan penyuluhan kesehatan tentang perawatan gigi. Adapun hasil uji statistik dengan menggunakan uji Wilcoxon dengan tingkat signifikasi $\alpha=0,05$ dan didapatkan harga $\mathrm{p}=0,001$ oleh karena itu nilai $\mathrm{p}<\alpha$ sehingga $\mathrm{H}_{0}$ ditolak. Hal ini berarti terdapat perbedaan yang berarti dari respon sikap siswa sebelum dan sesudah dilakukan penyuluhan kesehatan.

\section{PEMBAHASAN}

Berdasarkan hasil penelitian didapatkan data bahwa dari 33 responden, sebanyak 24 (72.7\%) responden dengan sikap negatif sebelum dilakukan penyuluhan kesehatan. Dilihat dari aspek pengalaman pernah atau tidaknya 
mendapatkan informasi, $13(54.2 \%)$ responden pernah mendapat informasi, sebanyak $6(25.0 \%)$ pernah mendapat informasi dari petugas kesehatan. Menurut Azwar (2015) adanya informasi baru mengenai topik tertentu dapat memberikan landasan pengetahuan baru bagi terbentuknya sikap. Menurut Notoatmodjo (2010), penyuluhan kesehatan merupakan faktor predisposisi terbentuknya pengetahaun. Peneliti berpendapat terdapat ketidaksesuaian antara fakta dan teori. Dimana siswa yang ada di SDN 601 Menanggal Surabaya pengetahuan mereka tentang perawatan gigi sudah bagus tetapi sikap serta perilaku yang mereka tunjukkan masih kurang baik hal ini dibuktikan dengan mereka masih menyukai makanan yang manis akan tetapi setelahnya tidak menyikat gigi ataupun berkumur, mereka juga mengatakan bahwa menggosok gigi pada malam hari jika mereka ingat, terdapat beberapa anak yang mengalami karies gigi. Menurut hasil penelitian sherlyta (2017) mengatakan bahwa kemungkinan pendidikan kesehatan gigi dan mulut yang disampaikan belum komprehensif terkait keseluruhan perawatan gigi.

Berdasarkan pengalaman pemeriksaan gigi secara rutin disekolah didapatkan hasil dari 23 responden yang tidak rutin memeriksakan gigi, didapatkan 18 responden bersikap negatif. Menurut Azwar (2015) pengalaman pribadi yang didapatkan haruslah meninggalkan kesan yang kuat, karena sikap akan lebih mudah terbentuk. Peneliti berpendapat bahwa dikarenakan siswa banyak yang tidak mempunyai pengalaman dalam pemeriksaan gigi secara rutin disekolah maka sikap yang mereka pun negatif.

Sesudah diberikan penyuluhan kesehatan terjadi perubahan hasil dimana sebelum diberikan penyuluhan kesehatan sebanyak $9 \quad(27,2 \%)$ responden dengan sikap positif dan sesudah dilakukan penyuluhan kesehatan sebanyak 23 (69.7\%) responden memiliki sikap positif. Menurut Notoatmodjo (2010), penyuluhan kesehatan salah satu fakor predisposisi pembetukan sikap. Menurut Syafrudin \& Yudia (2009), Penyuluhan kesehatan adalah suatu proses belajar yang dpaat merubah sikap seseorang dalam merespon sesuatu khususnya masalah kesehatan kea rah respon sikap yang positif. Peneliti berpendapat bahwa dimana seseorang yang mendapatkan informasi melalui penyuluhan kesehatan maka akan memiliki kecenderungan untuk bersikap positif karena wawasan individu telah terbuka oleh informasi, ini juga dapat dikarenakan aspek pengetahuan yang dimiliki individu kearah aspek yang positif. Dilihat dari sikap siswa-siswa setelah diberikan penyuluhan kesehatan tampak antusias dalam bertanya.

Berdasarkan uji statistika menggunakan Wilcoxon Sign Rank Test dengan tingkat signifikasi $\alpha=0,05$ didapatkan nilai $\rho=0,001$ maka $\mathrm{H}_{0}$ diTolak dan $\mathrm{H}_{1}$ diterima. Hal ini menunjukkan ada pengaruh penyuluhan kesehatan terhadap sikap siswa tentang perawatan gigi di SDN 601 Menanggal. Menurut Lawrence Green (1980) yang dikutip oleh Notoatmodjo (2010) bahwa penyuluhan kesehatan merupakan suatu bentuk pemberian tambahan informasi khususnya kesehatan yang bertujuan untuk menambah pengetahuan dan merubah sikap tentang kesehatan yang diperlukan oleh individu atau masyarakat, sehingga akan memudahkan terjadinya perilaku kesehatan. Kondisi tersebut sesuai antara teori dan fakta dimana terjadi perubahan sikap kearah respon positif sesudah diberikan penyuluhan kesehatan tentang perawatan gigi dan ini sejalan dengan penelitian Rahayu (2005) yang dikutip dalam penelitian Sherlyta (2017) yang mengatakan bahwa pemberian informasi kesehatan pada anak SD sangat penting baik bagi perkembangan gigi maupun jiwan dimana upaya ini dapat menghasilkan pengetahuan, sikap dan perilaku yang guna nya untuk meningkatkan tingkat kebersihan gigi dan mulut, upaya penyuluhan kesehatan ditujukan agar anak-anak dapat merawat kesehatan gigi dan mulut dengan baik. Selain itu penggunaan metode demonstrasi yang digunakan dengan alat peraga yaitu sikat gigi dapat menimbulkan minat siswa, memudahkan penyampaian informasi tentang perawatan gigi serta memudahkan siswa dalam penerimaan informasi, kemudian terdapat pula slide yang berisi teks, gambar serta video dan juga leaflet yang berisi gambar sehingga menarik perhatian untuk membaca serta merangsang penerimaan responden dalam membaca dan mendengarkan serta dapat memudahkan responden dalam memahami informasi yang disampaikan, juga adanya kesempatan responden untuk berpartisipasi dalam diskusi sehingga terjadi komunikasi 2 arah sehingga dapat meningkatkan pengetahuan seseorang untuk memelihara kesehatannya. Hal ini membuktikan bahwa pemberian penyuluhan kesehatan dapat memberikan kontribusi pada perubahan sikap seseorang sebagai upaya menggugah kesadaran responden untuk melakukan upaya agar tidak terjadi penyakit gigi dan yang lainnya. 


\section{KESIMPULAN}

Ada pengaruh penyuluhan kesehatan perawatan gigi terhadap sikap siswa, dimana penyuluhan kesehatan meningkatkan sikap positif siswa tentang perawatan gigi.

\section{DAFTAR PUSTAKA}

Azwar, Saifuddin. (2015). Sikap Manusia Teori Dan Pengukurannya. Yogyakarta: Pustaka Belajar.

Badan Penelitian dan Pengembangan Kesehatan Departemen Kesehatan Republik Indonesia. (2013). Riset Kesehatan Dasar 2013. Diakses 13 November 2018 dari http://www.google.id/url?q=http://www.de pkes.go.id?resources?download?general?H asil\%250Riskedas\%25202013.pdf\&sa=U\& ved=2ahUKEwjxmlacw-

DfAhWbiHAKHdj-

BgcQFjAAegQIAhB\&usg=AOvVaw3Jslw mrqlKAgCA5bfaG7GX

Badan Penelitian dan Pengembangan Kesehatan Departemen Kesehatan Republik Indonesia. (2014). Pusat Data dan Informasi Kementerian Kesehatan 2014. Diakses 13 Januari 2019 dari https://www.depkes.go.id/article/view/181 10200003/potret-sehat-indonesia-daririskesdas-2018.html.

Ghofur, A. (2012). Kesehatan Gigi Dan Mulut. Yogyakarta: Mitra Buku.

Lestari, T. (2015). Kumpulan Teori Untuk Kajian Pustaka Penelitian Kesehatan. Yogyakarta: Nuha Medika.

Notoatmodjo, S. (2012). Promosi Kesehatan dan Perilaku Kesehatan. Jakarta: Rineka Cipta.

Notoatmodjo, S. (2010). Ilmu Perilaku Kesehatan. Jakarta: Rineka Cipta.

Priyanti, Luh dan Ni Wayan Septarini. (2016). Determinan Karies Gigi Pada Anak Sekolah Dasar Di Pulau Nusa Penida, Klungkung Bali. Diakses 5 Desember 2018.dari https://www.google.co.id/url?sa=t\&source =web\&rct=j\&url=https://jurnal.undhirabali .ac.id/index.php/virgin/article/download/99 198\&ved=2ahUKEwjvjqri4iffAhULfd4KH XDwBSM4FBAWMAF6BAgHEAE\&usg $=$ AOvVaw1IDt8UFD8eO5mfhly0m1x.

Purwaningsih, Pande Putu., \& Sirat, Ni Made. (2016). Analisis Faktor Resiko yang Mempengaruhi Karies Gigi Anak SD Kelas V-VI Di Kelurahan Peguyangan Kangin Tahun 2015. Jurnal Kesehatan Gigi, 4(1). Diakses 14 Januari 2019 dari https://www.unud.ac.id/in/tugas- akhir1320015004.html.

Sherlyta, Monica. Tingkat Kebersihan Gigi dan Mulut Siswa Sekolah Dasar Negeri Di Desa Tertinggal Kabupaten Bandung. Diakses pada $\quad 7 \quad$ Mei 2019. http://www.google.com/url?sa=t\&source= web\&rct=j\&url=http://jurnal.unpad.acid/jk g/article/view/18607/0\&ved=2ahUKEwjS 4uf1KfiAhUFhuYKHd4JDDDIQFjAAegQ IBxAC\&usg=AOvVaw2asHIg0FUxq2euJ3 1cGDSz.

Sutrisman, Agus. (2013). Perbedaan Tingkat Pengetahuan, Sikap, Dan Tindakan Dalam Pemeliharaan Kebersihan Gigi Dan Mulut (PHPM) Sebelum Dan Sesudah Penyuluhan Kesehatan Gigi. Diakses pada 12 Januari 2019 dari http://www.google.com/url?sa=t\&source= web\&rct=j\&url=http://stieamm.ac.id/wpcontent/uploads/2017/11/2-Agus-

Sutrisman.pdf\&ved=2ahUKEwiT_93I_Pf AhUOT30KHdzMDskQFjAAegQIBRAB \&usg=AOvVaw1RKgwqGFJD6n8Wlaf8d $\mathrm{X} 7 \mathrm{j}$. 